\title{
Post-closure planning for Ranger Uranium Mine
}

\author{
H.D. Smith Northern Land Council, Australia
}

\begin{abstract}
The Ranger Uranium Mine is due for closure by 2021. The nature of potential long-term environmental impacts following closure indicates that a well-defined strategy is required if long-term stewardship is to be successful. A key consideration of this strategy is the inclusion of cultural and traditional ecological knowledge into closure plans in a manner that will allow Aboriginal landowners to assist with post-closure land management activities and regain their connectivity with the mined out land.

This paper seeks to summarise our earlier work on combining traditional and western scientific knowledge systems and demonstrate how they can be developed into plans for long-term stewardship, not only at Ranger but also at existing legacy sites and future mines. The key anticipated outcomes of these plans include reconstruction of a culturally appropriate and useable natural environment; which we believe represents best practice in mine closure.
\end{abstract}

\section{Introduction}

Australia's Northern Territory has a number of legacy issues related to the closure of mines of which Rum Jungle (Fawcett and Rider, 2011) is possibly the best known. The Northern Land Council (NLC), on behalf of its Traditional Owners, is working with the Northern Territory and Commonwealth Government in an effort to ensure that the mine will be rehabilitated to a standard such that the impacted land will be handed back and provide a viable future land use for Traditional Owners. The NLC is determined to ensure that similar legacy issues do not occur for the Ranger Uranium Mine, which is now approaching closure.

Creation of a sustainable post-closure environment for the Ranger Uranium Mine offers a unique set of challenges not only to the mine's operators, but also to the landowners who will ultimately act as stewards of the post-mining environment. These challenges are difficult because Ranger Mine:

- Is a uranium mine with a history of controversy, political and emotional fervour - which indicates the general public will seek the best possible outcomes from the closure process.

- Is set within the boundaries of a World Heritage Listed Park - which requires closure outcomes to meet specific and high standards.

- Has the potential for long-term radioactive contamination of not only the immediate site, but also the downstream environment if closure practices do not exceed current best practices.

Mining at the Ranger Uranium Mine commenced in 1981 and is due to cease in 2013, when the ore reserves of the main pit are exhausted. However, exploration of the Ranger Project area continues, with the best potential for continued production rests with the proposed mining of the Ranger 3 Deeps orebody. This may result in a delay to closure, which is currently anticipated for 2021.

Under existing Government Environmental Requirements (Australian Government, 2000) closure of the Ranger Project Area must be undertaken in a manner such that it meets the attributes for which Kakadu was nominated for World Heritage Listing. This includes a set of cultural attributes, which adds an additional layer of complexity to the closure process. Failure to meet these criteria may result in adverse public relations for Energy Resources of Australia, the mine's current owners.

In 2007, Mirarr (the Aboriginal landowners of the Ranger Project Area) and the NLC started work towards a method of addressing the damage done to Mirarr cultural attributes by uranium mining within the Ranger Project Area. The approach involved applying Traditional Ecological Knowledge (TEK) and Aboriginal land 
management practices to development of closure criteria for the mine (Smith, 2008) and through that, re-establishing connectivity with the land. The approach is similar to and drawn from more generic work being undertaken in Canada (Yukon Government, 2005) and New Zealand (Tipa and Tierney, 2006), is consistent with the aims of the United Nations Declaration on the Rights of Indigenous People (United Nations, 2007) and represents continuous improvement in stakeholder engagement and mine closure planning.

It is an approach that is now beginning to find wider acceptance in Australia by the mining industry seeking to develop meaningful Cultural Heritage Management Plans including application to alumina refineries (Smith, 2012), other uranium projects and to mine closure in the Philippines. Although we believe the project has significantly advanced the mining industry's understanding of the role traditional knowledge and practices can have in the mining process, there is still work to be done to develop tools to measure the success of this approach. We recognise that to date, no mine in the Northern Territory has taken this approach through to closure, so it remains largely theoretical.

Our ultimate goal is to have the post-mining landscape left in a manner that can support traditional lifestyles and continue to be managed using traditional methods in a manner identical to that which existed prior to mining, i.e. a truly sustainable environment. By adopting this approach, it becomes no longer acceptable for companies to mine for ore and leave the environment in a manner that is unfit for long-term further use.

Stewardship can be defined as an integrated programme of actions aimed at ensuring that all materials, processes, goods and services are managed throughout the life cycle in a socially and environmentally responsible manner (Commonwealth of Australia, 2006). We seek to tie it with environmental sustainability, which we consider to be a means of meeting the needs of the present without compromising the ability of future generations to meet their needs. Our consideration of stewardship is therefore confined here to management of the post-closure mining landscape, once financial support from a mining company or government is no longer available.

Having developed an approach that work towards this, we still need to develop tools and a strategy that can be used to measure its success in creating a post-mining environment that is sustainable and can be managed by people working at a traditional, subsistence level. This paper reports on a five-year plan that has been developed to allow for development of those tools through increased participation of traditional owners in rehabilitation of the Ranger Uranium Mine. Consequently, it represents an additional part of a work in progress and, as such, does not offer final outcomes. Final outcomes will only become available as Ranger Uranium Mine progresses closer towards closure.

\section{$2 \quad$ Methods}

The general strategy for Ranger Uranium Mine, which includes the cultural perspective, is represented in Figure 1. Work has previously been undertaken on two of the major elements of closure, closure criteria and landscaping, and is now commencing on the third, stewardship. The methods used for identifying relevant cultural information and integrating it with western scientific precepts have been developed through use of participative dialogue with traditional Aboriginal people. These and the methods by which they were individually developed are described in greater detail elsewhere (Smith, 2008, 2009, 2011, 2012).

Now that descriptors of the principle cultural components have been developed, their practical values need to be defined. Discussions were held with Energy Resources of Australia and a set of small-scale rehabilitation projects have now been identified by as suitable trials for testing our approach. Each trial is designed to foster increased involvement of the traditional landowners and offer opportunities, not only to re-establish connection with the land but also to develop metrics against which future success can be measured. 


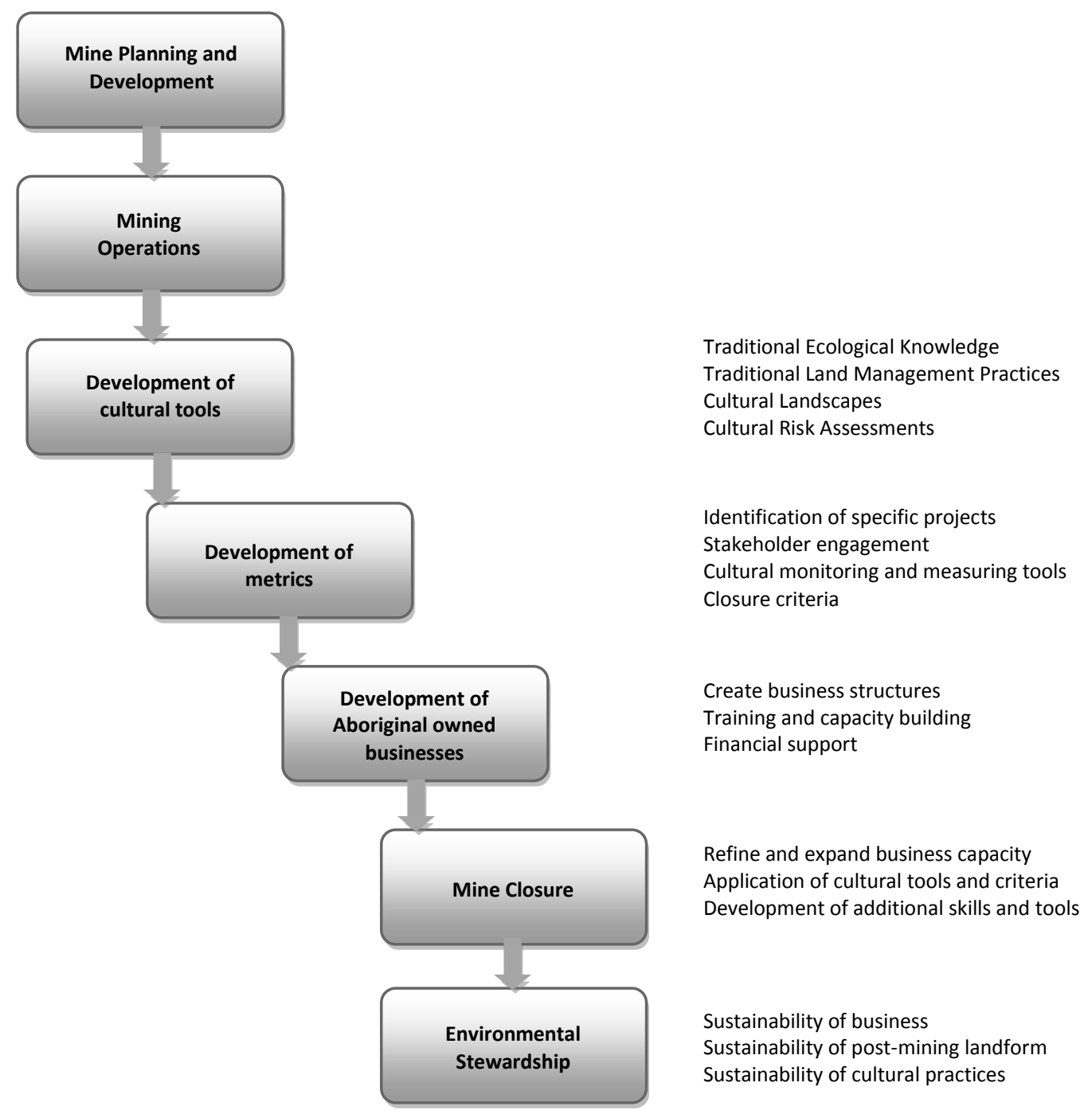

\section{Figure 1 Basic strategy used in planning for stakeholder engagement for post-closure at Ranger Uranium Mine}

\section{Discussion}

\subsection{Ranger Uranium Mine}

The key physical features of closure at the Ranger Mine involve backfilling of the pit voids to isolate radioactive tailings from the surface environment for a minimum 10,000 years, revegetation of reconstructed landforms and the use of sentinel wetlands and species for minimising water contaminant levels. Prior to 2007, the overall strategy was based around the use of analogue sites (Hollingsworth and Odeh, 2009) and landform modelling (Hancock et al., 2010). Foreseeable failures might be caused by erosion; radionuclide contamination of groundwater, surface water and bush food; and failure to re-establish sufficient abundance and diversity of vegetation patterns.

Scientific programmes that address these failures and key requirements for closure at Ranger are directed by the Alligator Rivers Region Technical Committee and an internal stakeholder Working Group charged with determining target closure values for a number of environmental values, e.g. surface water quality, 
has been established. However, it was not until 2009 that Mirarr were invited to become directly involved and serious thought given to their cultural requirements.

Mirarr have since indicated that the major cultural risks associated with closure of the Ranger are:

- That the recreated landscape would present few opportunities or even a desire to reconnect with and care for the damaged land.

- That time spent accessing the post-mining landscape will be restricted by the amount of residual radiation.

- Early surrender of the lease may lead to long-term problems with maintenance of cultural aspects of the recreated environment.

- That operational structures would not be in place to allow landowners to cope properly with repair to the environment should maintenance be required.

Application of the cultural tools developed with the assistance of Mirarr over the course of the past four years will partly assist in addressing the first of these risks, but other measures will also be required. For example, greater detail of how traditional people used the pre-mining environment needs to be collected if acceptable closure criteria related to radiation exposure of people are to be determined. An understanding of long-term distribution of radionuclides in groundwater and subsistence foods and how to quickly remediate these is needed if traditional hunting and gathering practices are to be re-established in the surrendered project area.

To assist with planning and development of an appropriate stewardship process, Energy Resources of Australia (ERA) in conjunction with Mirarr and the NLC has planned a series of pilot projects designed to embed this strategy into their final closure of the Ranger Mine (Jacobsen, 2012). These pilot projects increase in complexity and size, contribute to the wider closure and exit strategy for the mine and seek to re-establish Mirarr connection with land, improve engagement and build mutual respect. They include partially complete projects such as revegetation at Djarr-Djarr and removal of historic boreholes and infrastructure from the Boiweg-Almudj sacred site complex at the now closed Jabiluka Mine.

The forward strategy contains six projects that are scheduled for completion during 2012-13 and a seventh (which involves closure a pit) which will not be completed until 2017. None of these projects will result in direct relinquishment of land until the mine is formally closed, but each will provide a platform for achieving a number of cultural objectives including:

- Demonstrating the suitability of the landscaping, TEK and assessment tools for rehabilitation in restoring the landscape to an agreed beneficial land-use.

- Addressing existing legacy issues in a targeted and staged manner.

- Facilitating a focused engagement on targeted projects and knowledge sharing.

- Formally implementing the incorporation of traditional ecological and cultural knowledge into the closure process.

- Developing appropriate measuring tools.

- Piloting the development of fit-for-purpose restoration or closure criteria with flow on benefits to the life of mine closure strategy.

We anticipate that successful completion of these projects will develop capacity amongst Mirarr and within ERA to produce a strong system of co-management that will ultimately reach a point where Mirarr will be able to once again manage the land according to their cultural precepts.

The Ranger Mine has been constructed and operated against a thirty-year backdrop of political intervention, poor communication and environmental mishaps - all of which have led Mirarr to mistrust the company, the NLC and government. Thus far, the process we have used to engage Mirarr has led to a 
degree of trust, but we remain uncertain how strong their commitment to working on these projects will be. It seems clear, however, that unless trust can be re-established and co-management systems developed, ERA will be unable to fully divest its responsibilities and that integration of the post-mining landscape into the wider Kakadu National Park becomes less likely.

The final part of our strategy seeks establishment of an Aboriginal owned and operated business to ensure that any on-going maintenance of the rehabilitated landscape is done in a manner satisfactory to the traditional owners. This would allow the mining company to slowly withdraw from the tenement and transfer residual liability to the landholders in a manner where the landholders are not placed at a serious disadvantage - as we have seen with many existing legacy sites. Many of these are now characterised by acid mine drainage and/or erosion of waste rock and tailings dumps. Environmental monitoring is sporadic (if it is done at all) and unless the landowner or an interest group raises the alarm, the sites are generally left to decay further.

Although they have land management practices and a sound knowledge applicable to the Kakadu environment, it is doubtful Mirarr possess the technical capacity to ensure environmental sustainability of an area that has undergone an impact of this magnitude is maintained. It is hoped that the set of projects proposed by ERA will provide a platform on which capacity building amongst Mirarr can commence. The Australian Government, through Parks Australia, will also have a major role to play and should be used as a vehicle through which Mirarr capacity can be further enhanced in the medium to long-term. Whatever form this involvement may take, it is crucial that Mirarr remain included - because it is they who will ultimately bear the responsibility for environmental sustainability long into the future.

\subsection{Rum Jungle Mine}

The Mirarr engagement strategy developed for Ranger Mine is also now being applied by the NLC to other mines that are approaching closure (e.g. Woodcutters) or have legacy issues (e.g. Rum Jungle Mine). Rum Jungle is of special interest because it has parallels with Ranger, being used for mining of uranium and because the affected land is also part of a hand-back deal - in this case hand-back of the Finniss River Aboriginal Land Trust initiated by the Federal Government under the Aboriginal Land Rights Act. Under the deal this portion of the land cannot be handed back until such time as impacts of the Rum Jungle Mine have been fully mitigated (Commonwealth of Australia, 1981).

Mining of uranium first commenced at Rum Jungle in the 1950s and although the mine was rehabilitated, this has been sustainable and a significant environmental liability that is currently beyond the capacity of the landowners to bear now exists. The Australian Government has now accepted responsibility for the site and in 2010, A\$ 7.4 million were allocated for studies to feed into a decision about how to best resolve the environmental legacies (Fawcett and Rider, 2011). The situation is further complicated because there is active exploration for iron ore in the immediate vicinity and the potential for re-opening of the adjacent Compass polymetallic mine. Both have the potential for resumption of the Rum Jungle site, which would mean further environmental impact and delays in hand-back of the land.

The NLC and Kungurikany-Warai landowners are currently preparing a Cultural Heritage Management plan for Rum Jungle that uses cultural tools similar to those developed for Ranger Mine. This information will be submitted to the Australia Government for consideration in rehabilitation planning. Further information is to be obtained through additional consultations with other landowners downstream of the mine. The information gathering process has become complicated because the Kungurikany-Warai are fractured as a group and do not yet see a definite plan for rehabilitation and hand-back of the Rum Jungle site. Their main concern is that work towards rehabilitation will be completed, made promises fulfilled and the land handed over for further mining.

Regardless of how rehabilitation will proceed at Rum Jungle, we are again faced with dealing with decades of mistrust and a group of Aboriginal landowners who do not currently have the financial resources or industrial capacity to deal with environmental liabilities and deliver a sustainable outcome. However, a committee dedicated to identifying business opportunities and skills development has been set up and 
progress towards more formal inclusion of Kungurikany-Warai in the physical aspects of land management has commenced.

\subsection{New mines}

Ideally, a mining company should be preparing for effective stakeholder engagement and closure prior to opening the mine. Ranger and Rum Jungle mines both represent examples of less than ideal circumstances for development of a stewardship strategy for mine closure. However, our work at both of these mines has allowed development of a generic strategy engaging Aboriginal land-owners in closure and stewardship planning. This is shown in Figure 2. The process is essentially the same and it is only the timing of introduction of cultural tools, metrics and development of Aboriginal land management business that differs.

\section{KEY CONSIDERATIONS}

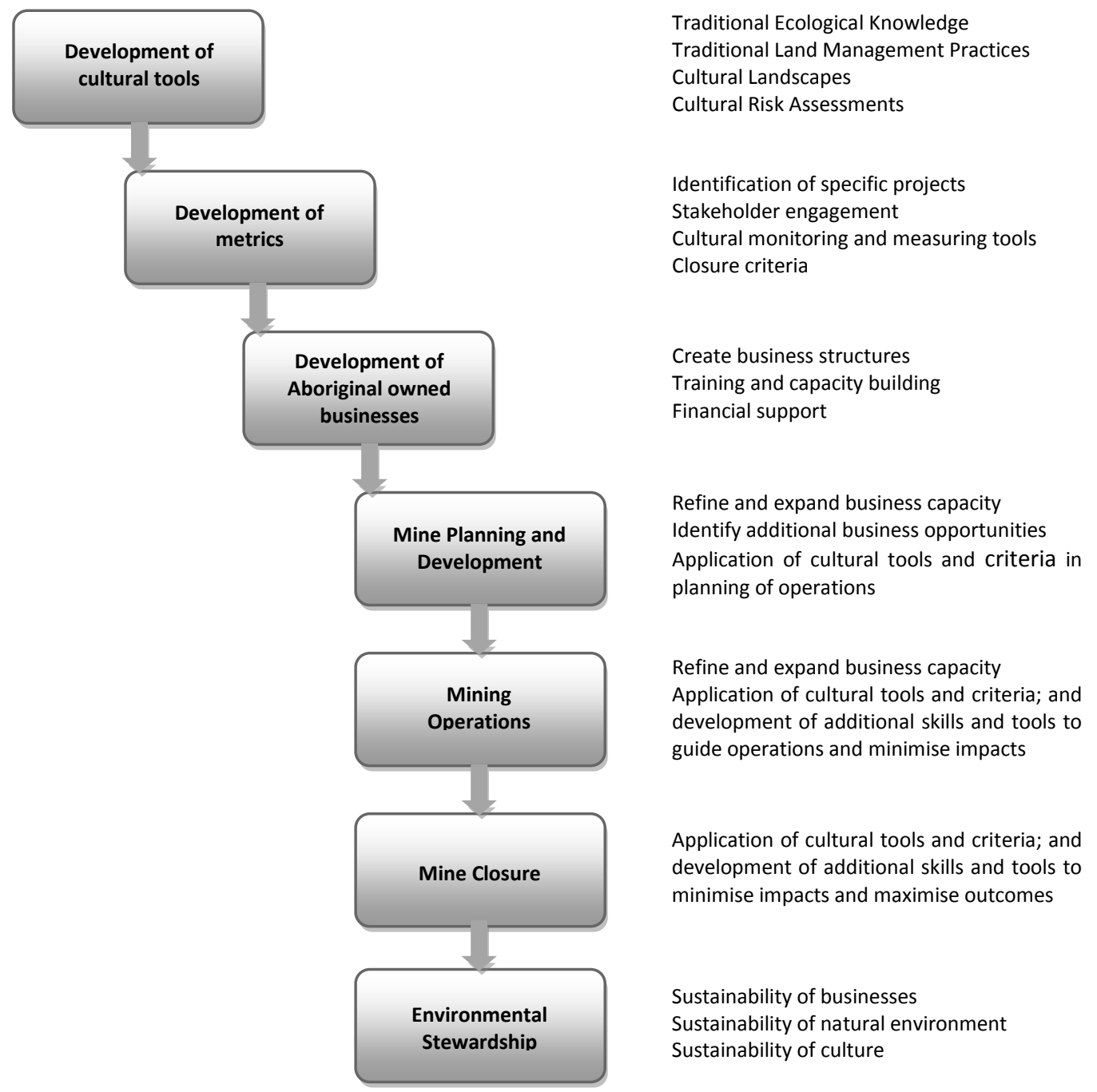

\section{Figure 2 Basic strategy used in planning for stakeholder engagement prior to development of new mines}

The wider strategy the NLC now applies to closure of mines is being applied through mining agreements negotiated prior to the commencement of mining. For new mines, the NLC and traditional owners encourage the development of Aboriginal owned and operated land management business that is integrated fully into the mining company's operations. The idea is to use cultural landscaping and traditional knowledge tools to determine an agreed final land use and guide mining operations in a manner 
that it can be achieved with minimal cultural disruption. This strategy allows TEK and traditional land management practices as tools to assist the company throughout the operational, closure and rehabilitation phases of the project. With sufficient on-going support from the company, we believe this type of business can become self-sufficient and capable of providing a sustainable system for stewardship of the post-mining environment.

\subsection{Improving mine closure practice}

Prior to the 1970s, many mines were abandoned with little thought given to dealing with long-term negative environmental impacts. Through a combination of increased social concerns for the environment and improved mining and rehabilitation technology and techniques, the standard of mine closure practice has been slowly and continuously lifted. Further advancement has come with greater consideration of the rights of indigenous people, leading to development of strategies and tools through which Aboriginal stakeholders and their unique ecological knowledge and cultural and spiritual concerns can be integrated into the debate. This represents an additional and necessary step change in improving mine closure practice.

The use of concepts such as triple bottom line (TBL), expressed in terms of social, economic and environmental impacts, and now quadruple bottom line ( $Q B L$ ) as management tools that can be used to guide mining operations has provided further assistance. QBL is expressed terms of financial, ecological, social and cultural (or spiritual) aspects that ensure operations meet the needs of the present without compromising the ability of future generations to meet their own needs (United Nations, 1987). It is an emerging concept that has an integral part to play in sustainable development and is becoming a part of corporate consciousness and the 'social licence to operate'.

We believe the strategy and cultural tools described by this on-going project are unique and people can assist mining companies to address the cultural and spiritual factors associated with the QBL. Importantly, they are derived by Aboriginal people and therefore reflect their cultural mores, making them both practical and consistent with Article 5, Article 11, Article 24 (1), Article 25, Article 29, and Article 31 (1) of the United Nations Declaration on the Rights of Indigenous People (United Nations, 2007). These Articles aim to support the right of indigenous people to maintain and protect their natural environment, their culture and the links that exist between them. In doing this, we believe that they should now be considered current best practice.

\section{Conclusions}

The need to demonstrate that cultural attributes can be 'rehabilitated' to World Heritage standards for the Ranger Uranium Mine has driven the development of tools that encourage full engagement of Aboriginal stakeholders. These are integral to a wider strategy that is being developed for mining operations, mine closure and stewardship of the post-mining environment. Ideally this strategy is applied via agreements negotiated prior to commencement of mining, but with some minor modifications it can be applied at any stage of the mining process.

Site-specific plans are therefore required for each mine. At Ranger and Rum Jungle mines, the capacity to fully utilise this strategy is limited because it was not in place prior to mining and can now only be developed in a manner that focuses on mine closure and the final land use. It cannot be used in those cases to direct or guide mining so that cultural impacts are minimised throughout the operational phase.

However, taking this approach can lead to improved stakeholder engagement, greater transparency, build increased capacity amongst Aboriginal people to effectively manage the post-mining environment and inevitably re-establish the cultural connection to the environment where it has been lost.

We believe these relatively simple tools should be considered current 'best practice' because they are consistent with the goals of the United Nations in encouraging greater engagement with indigenous 
peoples. Provided that the process can remain sensitive to cultural change and enhance connectivity of people with their land, these tools can play an important role in guiding impact assessments, mine development and shaping the outcomes of the post-mining landscape.

\section{Acknowledgement}

The author acknowledges the kind assistance of Energy Resources of Australia for permitting discussion of part of its forward planning for closure.

\section{References}

Australian Government (2000) Environmental Requirements of the Commonwealth of Australia for the Operation of Ranger Uranium Mine, Department of the Environment, Water, Heritage and the Arts, Canberra.

Commonwealth of Australia (2006) Stewardship - Leading Practice Sustainable Development Program for the Mining Industry, Commonwealth of Australia, Canberra, 2006.

Commonwealth of Australia (1981) Finniss River Land Claim, Report by the Aboriginal Land Commissioner, Mr Justice Toohey, to the Minister for Aboriginal Affairs and to the Administrator of the Northern Territory, Australian Government Publishing Service, Canberra.

Fawcett, M. and Rider, M. (2011) The Rum Jungle Project, AusIMM Bulletin 2, 2011, pp. 16-20.

Hancock, G.R., Lowry, J.B.C., Coulthard, T.J., Evans, K.G. and Moliere, D.R. (2010) A catchment scale evaluation of the SIBERIA and CAESAR landscape evolution models, Earth Surface Processes and Landforms, Vol. 35, Issue 8, pp. 863-875.

Hollingsworth, I.D. and Odeh, I.O.A. (2009) Simulation and Assessment of Mine Landscape Reconstruction Using Analogue Landform and Environmental Design Criteria, ICECS '09 Proceedings of the 2009 Second International Conference on Environmental and Computer Science, pp. 62-65.

Jacobsen, N. (2012) Progressive Rehabilitation 2012-2017, Pilot Projects, Energy Resources of Australia Internal Paper, March 2012.

Smith, H.D. (2008) Using Traditional Ecological Knowledge to develop closure criteria in tropical Australia; in Proceedings Third International Seminar on Mine Closure (Mine Closure 2008), A.B. Fourie and M. Tibbett, I.M. Weiersbye, P. Dye (eds), 14-17 October 2008, Johannesburg, South Africa, Australian Centre for Geomechanics, Perth, pp. 47-56.

Smith, H.D. (2009) Strangers in a foreign land - developing cultural closure criteria for mines in Australia's Northern Territory, in Proceedings Fourth International Conference on Mine Closure (Mine Closure 2009), A.B. Fourie and M. Tibbett (eds), 9-11 September 2009, Perth, Australia, Australian Centre for Geomechanics, Perth, pp. 3-12.

Smith, H.D. (2011) Aboriginal culture, socio-economics and the social licence to operate, in Proceedings of the First International Seminar on Social Responsibility in Mining, September 2011, Santiago, Chile, pp. 152-154.

Smith, H.D. (2012) Indigenous culture, socio-economics and the social licence to operate, in Proceedings of the Ninth International Alumina Quality Workshop, March 2012, Perth, Australia, pp. 37-42.

Tipa, G. and Teirney, L. (2006) Using the Cultural Health Index: how to assess the health of streams and waterways, Ministry for the Environment, Wellington, New Zealand.

United Nations (1987) Report of the World Commission on Environment and Development: Our Common Future, Annex to document A/42/427 - Development and International Co-operation: Environment, Geneva.

United Nations (2007) United Nations Declaration on the Rights of Indigenous People, Resolution 61/295, UN General Assembly, September 2007.

Yukon Government (2005) DRAFT Yukon Mine Site Reclamation and Closure Policy for New Mines, Whitehorse, Canada. 